\title{
INTELECTUAIS PARANAENSES E AS CONCEPÇÕES DE UNIVERSIDADE: 1892-1938*
}

Névio de Campos**

\section{RESUMO}

Este artigo analisa a trajetória, os debates e os projetos dos intelectuais em torno do ensino superior à luz do contexto histórico paranaense, do estudo que está circunscrito entre 1892 e 1938, discutindo os processos de constituição dos grupos, as suas interlocuções com as vertentes teóricas em geral, as suas idéias e intervenções culturais, bem como suas relações com o Estado e com os grupos no cenário do Paraná desse período. Discorre sobre as contribuições dos intelectuais paranaenses ao processo de constituição e organização do ensino superior e enfatiza que o papel desses grupos foi criar instituições culturais no contexto paranaense, sem esquecer o contexto político-cultural do Brasil e da Europa como pano de fundo da criação do ensino superior. Apóia-se em um conjunto de documentos escritos e organizados por esses intelectuais, os quais nos possibilitaram afirmar que esses grupos estabeleceram instituições de ensino superior e mobilizaram os principais personagens dos espaços culturais e políticos curitibanos para se colocarem a serviço do projeto universitário no estado do Paraná.

Palavras-chave: Intelectual. Universidade. Formação humana.

\section{INTRODUÇÃO}

Este artigo analisa o papel dos grupos paranaenses no processo de organização do ensino superior com base na discussão estabelecida por Antonio Gramsci. Assim, a construção teórica desse pensador será fecunda para este estudo, particularmente, o conceito de intelectual, pois

\footnotetext{
* Artigo recebido em 17/5/2007 e aprovado em 11/8/2007.

** Doutor em Educação; Professor no Departamento de Educação da Universidade Estadual de Ponta Grossa.
} 
entendemos que os grupos que discutiram as idéias de universidades no Paraná se autodenominavam portadores de uma missão cultural para esse estado.

Na nossa análise, privilegiamos as funções dos intelectuais, suas iniciativas no campo político, na direção de projetos educacionais e menos a sua formação e a sua obra literária, filosófica ou científica. Segundo o filósofo italiano,

o modo de ser do novo intelectual não pode mais consistir na eloqüência, motor exterior e momentâneo dos afetos e das paixões, mas num imiscuir-se ativamente na vida prática, como construtor, organizador, "persuasor permanente”. (Gramsci, 2001, p. 53, sem grifo no original)

A experiência formativa é mediada pela intervenção daqueles que assumem as funções de organizadores dos projetos culturais. Essa função mediadora é incumbência dos intelectuais que, para Gramsci, são aqueles que participam das práticas sociais, sintetizam, sistematizam as idéias de um grupo social e propõem projetos de ação. É com base nesse conceito que analisamos as intervenções dos intelectuais que foram organizadores da vida prática, sintetizando e sistematizando os projetos de ensino superior no Paraná.

De modo sintético, visamos analisar o papel dos intelectuais no processo de discussão e implementação de instituições universitárias no estado do Paraná, ou seja, compreender as diferentes concepções de universidades sistematizadas no período que está circunscrito entre 1892 e 1938.

Projetos UnIVERSITÁRIOS PARANAENSES: ENTRE AS LETRAS, A PREPARAÇÃO PROFISSIONAL E A FORMAÇÃO DE UMA ELITE INTELECTUAL

Rocha Pombo e a idéia de universidade: um percurso entre as letras e a formação profissional

José Francisco da Rocha Pombo, ${ }^{1}$ em 1892, propôs a criação de uma universidade na capital paranaense. Para o Paraná, aquela ação foi peculiar naquele período, pois as discussões sobre a criação da universidade ficaram centralizadas na capital brasileira. ${ }^{2}$ 
A ação de Rocha Pombo em defesa da criação da universidade no Paraná não foi precedida de discussão teórica acerca de sua concepção sobre essa temática, ou melhor, ele não produziu obras em que a temática do ensino superior tenha sido diretamente objeto de discussão. Não obstante, é possível identificar em algumas obras, nas quais Pombo tratou da educação, reflexões sobre o papel da universidade no processo de formação dos indivíduos. Essa ausência de produção teórica é possível de ser entendida à medida que compreendemos a trajetória de Rocha Pombo, homem fortemente vinculado à imprensa e ao debate político paranaense.

A Lei n. 63, de 10 de dezembro de 1892, que concedeu, por cinqüenta anos, a Rocha Pombo o direito para estabelecimento de uma universidade na capital do Paraná, determinava que o Estado comprometia-se a pagar ao concessionário uma taxa de juro de seis por cento ao ano sobre o capital efetivamente empregado, estabelecendo o máximo de mil contos de reis, a contar da data da inauguração dos cursos; previa, também, a isenção de todos os impostos devidos ao Estado pelo material destinado ao estabelecimento de ensino. A lei determinava no artigo quarto que

a universidade compreenderá, pelo menos, os seguintes cursos: Direito, Letras, Comércio, Agronomia, Agrimensura e Farmácia. Além do curso geral, cujos programas ficarão sujeitos à aprovação do Congresso Legislativo. (Leis do Paraná, 1892, p. 262, grifo do autor)

É interessante ressaltar que a universidade se constituía pelos cursos de letras e formação profissional, o que evidencia a concepção de um projeto diferenciado de ensino superior para aquele contexto histórico do Brasil e do Paraná, no qual existiam apenas as faculdades de formação técnico-profissional. Ademais, o artigo quinto estabelecia que, após a inauguração da universidade, seriam extintos o Ginásio Paranaense e a Escola Normal, pois ambos constituiriam uma das seções da instituição de ensino superior, caracterizando uma ação pioneira, pois a formação de professor ganhava o status de formação superior, o que naquele momento pouco se discutia nas principais cidades do Brasil.

A universidade cumpria um papel fundamental no projeto educativo proposto por Rocha Pombo, pois seria responsável pela formação 
do sábio, capaz de dirigir a cidade, bem como de promover a elevação intelectual e moral dos outros homens. Ressaltamos que, para esse intelectual, os sábios não eram somente os que se dedicavam aos estudos científicos, mas particularmente aqueles que se ocupavam do debate das letras e da filosofia.

O contato estreito com as letras, a partir de 1881, consubstanciou o seu projeto de 1892. No século XIX, a universidade representava o lugar apropriado para formar a elite intelectual, aquela que deveria dirigir os rumos da nação, dos estados, das cidades, enfim, capacitada para promover a formação moral e intelectual de seu povo. Rocha Pombo prescreve à universidade do Paraná, configurada nas faculdades de ciências e letras, o dever de formar uma intelectualidade capaz e comprometida com a modernização da cidade e do estado, bem como com o desenvolvimento intelectual e moral dos indivíduos. O saber científico era importante no sistema de organização da universidade, mas a formação do cientista não deveria ser a sua única missão. Por isso, a presença das letras e da filosofia foi marcante no projeto de Rocha Pombo, embora não tenha feito referência à existência do programa do curso ou da faculdade de filosofia. No entanto, ao percorrermos sua obra Petrucello, observamos que a filosofia ocupava papel fundamental no processo de formação dos indivíduos; nessa obra, muitas de suas idéias postuladas no início dos anos de 1880 foram reafirmadas, pois, como vemos, para ele,

Filosofia é todo o trabalho de indagação feito pelo espírito humano em busca da verdade; ciência é a consubstanciação das verdades que a filosofia apurou. Crê na filosofia, mas não crê na ciência dos homens. Comparando o que eles conseguiram saber com o que eles ignoram, isto é, os elementos da filosofia com o material científico, diz que o mais sábio dos homens não passa de um miserando mortal. Acha impróprio que se diga filosofia positiva, salvo se o termo positivo determina apenas um ponto de vista. Assim mesmo, a filosofia positiva nunca satisfará o espírito humano. (РомBo, 1892, p. 27, grifo do autor)

Ao postular a presença das faculdades de letras e de formação de professores, Rocha Pombo se punha ao lado dos defensores de um projeto considerado secundário por grande parte da intelectualidade brasileira.

$\mathrm{O}$ que foi determinante para que este intelectual paranaense pensasse nesse modelo de universidade? A íntima relação com as letras 
e com a filosofia indica as razões que impediram Rocha Pombo de propor uma universidade comprometida exclusivamente com o utilitarismo do saber, ou melhor, a interlocução que estabeleceu com diferentes pensadores foi responsável pelo processo de elaboração de seu projeto universitário. $^{3}$

O seu projeto de ensino superior pode ser aproximado da concepção humboldtiana de universidade, na qual se devia conjugar educação utilitária com formação desinteressada, embora não tenhamos localizado referências de Rocha Pombo ao projeto universitário alemão; porém, citava Humboldt, bem como Ernest Renan, autor francês admirador do projeto universitário alemão. A aproximação entre o seu projeto e a concepção humboldtiana de universidade se sustenta à medida que analisamos a sua trajetória intelectual e os cursos que seriam implantados.

Segundo Rossato (1998, p. 137), "os filósofos alemães, mais que ninguém no mundo, pensaram e escreveram sobre a idéia de universidade, e, em nenhuma parte, ela se encarnou mais que na Alemanha". A implantação do modelo alemão, cuja experiência tornou-se referência para inúmeros países, deu-se com Guilherme Humboldt, diretor do Culto e da Instrução Pública do Ministério do Interior da Prússia.

A relação entre o modelo alemão e o projeto de Rocha Pombo pode ser estabelecida com base na indissociabilidade entre o conhecimento utilitário e o saber desinteressado. Nesse aspecto, este intelectual paranaense aproximava-se do modelo germânico; porém, esse modelo teve uma série de outros elementos que não foram possíveis de ser depreendidos da obra de Rocha Pombo, como, por exemplo, a liberdade de ensinar e de pesquisar. No projeto alemão,

A universidade é uma comunidade de pesquisadores que gozam de liberdade acadêmica, rejeitando, portanto, o controle ou a cooptação; os professores gozam de liberdade de expressão, sem censura política no exercício do ensino. A universidade tem autonomias pedagógica, administrativa e financeira. (RossaTo, 1998, p. 139)

A faculdade de filosofia representava o centro da universidade alemã, pois nesta os estudantes deveriam ser formados; ela exercia o papel organizador das faculdades de medicina, de direito e de teologia, pois a formação do universitário deveria ter em sua base o ensino filosófico, ou melhor, no pensamento humboldtiano, os acadêmicos deveriam ser, primeiramente, estudantes de filosofia. 
No projeto universitário de Rocha Pombo não houve indicação da criação da faculdade de filosofia. No entanto, esse intelectual acreditava que a filosofia constituía o projeto da humanidade de busca da verdade, ou melhor, a filosofia se caracterizava pela procura da verdade, pois ele não associava a filosofia ao encontro da verdade; para ele, o filósofo não tem a verdade, mas está à sua procura, sendo essa busca permanente. Por outro lado, a ciência é a consubstanciação das verdades apuradas pela filosofia. Não obstante, as verdades científicas não são perenes. Por isso, Rocha Pombo dizia que Petrucello acreditava na filosofia e não na ciência. Se considerarmos esta reflexão, é possível sustentar que a filosofia ocupava no seu projeto cultural a centralidade da formação humana.

\section{Projeto de 1912: Universidade do Paraná e a devoção à ciência aplicada}

Vinte anos se passaram e nasceu a Universidade no Paraná. ${ }^{4}$ Para Vitor do Amaral e Nilo Cairo, no decorrer dessas duas décadas, a capital paranaense construiu as bases necessárias para a criação da universidade, justificando, portanto, a proposição de um projeto universitário para a cidade.

Segundo Vitor do Amaral, "a Universidade do Paraná surgiu, como sabeis, quase ex-abrupto, sem grande período de incubação: - foi o produto de um gesto quase impulsivo, uma obra de audácia - audentes fortuna juvat" (RELATÓRIO..., 1913, p. 3). A UP constituiu o espaço que institucionalizou o discurso dos especialistas. Os discursos do médico e do engenheiro assumiram a força de verdade entre a elite curitibana a partir do início do século XX.

O grupo responsável pela criação da UP, em 1912, contou com a coordenação de Nilo Cairo e de Vitor Ferreira do Amaral. Segundo Macedo Filho, professor da Faculdade de Direito,

Nilo Cairo, Vitor do Amaral, Daltro Filho e Flávio Luz foram os paladinos intemeratos da idéia agigantada que se deveria concretizar no empreendimento que apesar dos anos decorridos não encontrou parelhas no Paraná e mesmo em outros Estados de maior riqueza e população. (REvista ACADÊMICA, 13 jun. 1934, p. 4-5)

O grupo que se reuniu para estabelecer a universidade foi composto, além destes citados, de Panfilo de Assunção, presidente da 
Associação Comercial (assumiu a cadeira Parte Geral do Direito Civil, Direito Civil das Obrigações); professor Julio Teodorico Guimarães (responsável pela cadeira de Caligrafia e Datilografia no curso de Comércio); Reinaldo Machado (assumiu a cadeira de Clínica Ginecológica e Ginecologia; e outra de Obstetrícia); Hugo Simas (responsável pela cadeira de Economia Política e Finanças, Contabilidade do Estado); Euclides Beviláquia (assumiu a cadeira de Teoria e Prática do Processo Civil e Criminal); João David Perneta (responsável pelas cadeiras de Geometria Analítica e de Cálculo Infinitesimal).

Nilo Cairo assumiu várias cadeiras na área médica; ele foi considerado pelo grupo como principal fundador; estudou na Escola Militar e na Escola de Medicina do Rio de Janeiro. Vitor do Amaral, considerado pelo grupo como "reitor de sempre", recebeu sua formação intelectual na Faculdade de Medicina do Rio de Janeiro. Grande parte desses professores recebeu formação nas escolas de Direito e de Medicina ou na Escola Militar e escolas politécnicas do Rio de Janeiro e de São Paulo, estando portanto atrelada a um ambiente cultural em que a mentalidade positiva e científica era hegemônica, o que caracteriza um elemento fundamental para compreender a concepção de universidade, bem como as funções que deveriam ser exercidas por ela.

Nilo Cairo da Silva e Vitor do Amaral foram instruídos neste contexto de efervescência das idéias do positivismo, do darwinismo, do spencerismo, do materialismo, do tainismo e de tantos outros, o que explica por que o projeto de 1912 estava imbuído dessas idéias. Nilo Cairo permaneceu fiel às idéias de Comte, pois é o que atestava a sua oração de paraninfo, intitulada Liberdade de ensino e liberdade profissional, proferida em 1914, em homenagem ao primeiro grupo de alunos que fez colação de grau na UP, na qual afirmava que a escola positiva

tem sido [...] no nosso país, não somente a única a invocar, em favor das reformas que prega, os altos interesses coletivos da regeneração social, mas também de todas a mais apaixonada, a mais extremada, a mais ativa, a mais rica de razões elevadas, na propaganda da liberdade de ensino. (SILVA, 1914, p. 16)

A constituição da UP contou com a participação de inúmeros intelectuais que exerciam suas atividades profissionais e políticas na 
capital paranaense, pois uma grande parcela da elite curitibana participou do evento de lançamento da pedra fundamental dos alicerces da UP, no dia 31 de agosto de 1913. Com base no relatório geral de 1913, foi publicado, no jornal Comércio do Paraná, um artigo com a relação dos nomes das autoridades presentes nesse evento, entre os quais destacamos Carlos Cavalcanti (presidente do Paraná), D. João Braga (bispo da diocese de Curitiba), Cândido de Abreu (prefeito de Curitiba), Afonso Camargo (vice-presidente do Paraná) e Arthur Franco (secretário da Fazenda), bem como o Clube Curitibano, representado por Hugo Simas, Sebastião Paraná e Enéas Marques, representantes dos jornais Comércio do Paraná e República, Emiliano Perneta (Centro de Letras) e diversos professores, entre eles os que compunham o grupo fundador da universidade. Grande parte dessas autoridades exerceu atividade docente ou administrativa na universidade; Cândido de Abreu ${ }^{5}$ e Afonso Camargo, ${ }^{6}$ respectivamente, prefeito e vice-presidente, foram professores da universidade. Em outra passagem, Vitor do Amaral afirma o seguinte:

A existência de nossa Universidade é, pois, uma realidade; ninguém pode mais considerá-la uma vã tentativa arriscada a abortar; a regularidade com que funcionaram as aulas dos diversos cursos e a seriedade com que foram realizados os exames finais, em que não foram raras as reprovações, tudo demonstra que se trata de uma instituição com todos os requisitos de viabilidade. (RELATóRIO..., 1913, p. 7)

A presença dos especialistas entre os dirigentes do estado caracterizava a importância que foi dada ao pensamento técnico no processo de constituição da modernização do Paraná. A UP representava o espaço de formação desses arautos da modernização. Nesse sentido, os seus fundadores contaram com a participação e o apoio da elite dirigente do Paraná no processo de criação da universidade, ou melhor, os intelectuais, particularmente Nilo Cairo e Vitor do Amaral, aglutinaram em torno de seu projeto diversos personagens importantes e influentes no cenário político e cultural de Curitiba e do Paraná.

As faculdades de Engenharia, de Medicina e de Direito constituíram a UP. A julgar pelas faculdades, percebemos que a formação profissional foi considerada primordial, pois os cursos criados, além daqueles que compunham os nomes das faculdades, foram Comércio, 
Obstetrícia, Odontologia, Agronomia, Cirurgia e Medicina Veterinária. Estavam excluídos os cursos ou as faculdades de filosofia, de ciências e de letras, bem como o curso de formação de professores.

Havia, no Paraná, de acordo com esse grupo, necessidade de criar espaços propícios ao ensino das ciências e da formação profissional. No dizer de Nilo Cairo,

Grande número de moços estudiosos e ávidos de saber emigram todos os anos para outras terras em busca de academias para se prepararem em cursos que os habilitem a uma profissão distinta. Outros, não podendo sair, por ausência de recursos pecuniários, aqui ficam vegetando e lamentando a falta desses focos de ciência indispensáveis à cultura que ambicionam. (RelatóRIO..., 1913, p. 19)

O discurso oficial de inauguração da UP, proferido em 19 de dezembro de 1912, por Manoel de Cerqueira Daltro Filho, é exemplar para o entendimento das principais preocupações daqueles intelectuais. Daltro Filho criticou o modelo universitário clássico, indicando o ensino especulativo como maior problema. O projeto de 1912 não representou o ideário universitário defendido pelos prussianos; ao contrário, expressava o modelo que visava apenas a formação profissional da juventude, embora se denominasse de universidade.

A UP foi criada segundo o modelo das faculdades existentes no Brasil. A diferença é que não estavam isoladas do ponto de vista administrativo, pois deveriam funcionar no mesmo local e serem regidas pelo mesmo estatuto. É interessante observar que a verdadeira universidade, na concepção do grupo, consistia no agrupamento das escolas isoladas existentes no Brasil, sendo desconsiderada a inclusão de cursos ou faculdades de humanidades. A universidade, na concepção do grupo, deveria contemplar os saberes que exerciam uma função social imediata. Para Daltro Filho,

Baste-nos referir que à Universidade do Paraná, escorando-se nas magnas conquistas da Psicologia, se traçara um destino utilitário e sério: abreviar-se na cultura a um tempo sólida e restrita às experiências profissionais, visando formar homens que se andem com êxito pelas vias tortuosas da existência, imperturbáveis e sós. (RELATÓRIO..., 1913, p. 79) 
Vitor do Amaral reforça o sentido atribuído à ciência ao dizer que a universidade deveria estabelecer "o ensino de agricultura racional, científico e prático, a fim de desaparecer a errônea crença de que o Paraná só pode produzir com vantagem erva-mate e pinheiros" (RELATÓRIO..., 1914, p. 206). No dizer de Daltro Filho,

A ciência é apenas um guia, que nos torna claudicantes por entre as aparências da existência universal e vai nô-las revelando, na preocupação nobílima de uma forte intimidade, entre a nossa própria consciência e a realidade das cousas que nos cercam. (RelatórIo..., 1913, p. 80)

Mais adiante, indicava o autor, "as suas verdades, severamente demonstradas, são as próprias verdades positivas: não se engarçam numa série de proposições metafísicas, mais ou menos despidas de sentido; coordenam-se, amarradas em sistemas de relações infrangíveis" (p. 80). Não havia dúvida para o grupo; o saber científico deveria ser a única base na formação do bacharel, já que era o único conhecimento que fazia sentido ao contexto paranaense. Esse grupo não estava preocupado em desenvolver o estudo científico desinteressado, pois os saberes científicos deveriam ter uma aplicação imediata às questões da época e do Paraná. De acordo com Vitor do Amaral,

Urge que, com a divulgação de um estudo acurado de zootecnia e de patologia vegetal, se consiga restaurar a nossa indústria pastoril em decadência e restabelecer com proveito a cultura de cereais e frutas, que outrora eram aqui colhidas profusamente sem esmero de cultivo. (RelatóRIO..., 1914, p. 206-207)

O projeto do grupo paranaense, em 1912, não representou rompimento com a universidade do modelo napoleônico, pois o fato de criar universidade e não faculdades não representava o entendimento de ensino superior como lócus da ciência pura e do conhecimento desinteressado. No Brasil, a noção de universidade como expressão da ciência pura se constituiu nos anos de 1930, particularmente com a vinda de professores estrangeiros, quando a formação de pesquisadores foi entendida como uma das atribuições da universidade. Portanto, a universidade de 1912 tinha como preocupação fundamental a formação de profissionais para ocupar as funções burocráticas das esferas estatais, bem como 
desenvolver o progresso técnico no Estado do Paraná, contribuindo com o projeto de constituição de uma nação moderna, pois naquele momento se observava a aproximação explícita entre os especialistas e os grupos dirigentes do estado.

Faculdade de Filosofia, Ciências e Letras do Paraná: tecendo um diálogo entre filosofia, ciência e formação profissional

O grupo fundador afirmava que, "em pleno centro da futura cidade universitária curitibana, ergue-se imponente e majestosa, elegante em seus contornos, severa na suas linhas, a Faculdade de Filosofia, Ciências e Letras do Paraná, orgulho do ensino superior de nosso Estado" (ANUÁRIO DA FACULDADE..., 1943, p. 89). A FFCL, criada em 1938, foi produto da ação da intelectualidade católica.

Desse modo, no século XX, na capital do Paraná, foi com o laicato católico que se iniciou a discussão em torno da inclusão da filosofia como base da formação universitária. O texto de Lacerda Pinto, ${ }^{7}$ de 1932, foi o ponto de partida desse debate; o curso de Filosofia, ministrado no Círculo de Estudos Bandeirantes (CEB), ${ }^{8}$ entre 1935 e 1936, representou uma conquista significativa em favor da filosofia católica.

A primeira iniciativa da criação da FFCL foi coordenada por Omar Gonçalves da Mota, Carlos de Paula Soares e Homero de Melo Braga. $\mathrm{O}$ primeiro vinha das Ciências Jurídicas, onde exercia docência nas cadeiras de Direito Industrial, Legislação do Trabalho e Economia Política na Faculdade de Direito. Os dois últimos vinham da área da Medicina; o segundo formou-se na Faculdade de Medicina de Porto Alegre; o último formou-se no Paraná. No dia 26 de fevereiro de 1938, no salão nobre do prédio das faculdades de Medicina, Direito e Engenharia,

reuniram-se diversos professores para constituir a primeira mesa que iria presidir aos trabalhos preliminares da fundação da Faculdade. Nessa ocasião, foi unânime aclamada a primeira diretoria - diretor, Dr. Omar Gonçalves da Mota; vice-diretor, Dr. Carlos de Paula Soares; e secretário, Dr. Homero de Melo e Braga. (ANUÁrIo DA FACULDADE..., 1940-1941, p. 5)

Naquele momento, "o Paraná teve a máxima honra em ver fundada nesta capital, a 26 de fevereiro de 1938, a sua Faculdade de Filosofia, 
Ciências e Letras" (ANUÁRIO DA FACULDADE..., 1940-1941, p. 5), sendo, posteriormente, estabelecido o regimento interno da instituição, no qual foi determinado que a faculdade assumiria o curso complementar do Ginásio Paranaense, recebendo o valor correspondente à sua manutenção, bem como solicitaria uma subvenção ao governo do estado do Paraná.

Já na reunião de criação da referida faculdade, estavam Loureiro Fernandes e pe. Jesus Ballarin, o que caracterizou a participação de representantes do grupo católico. O projeto universitário, "obra nascida de sadio idealismo de uma elite intelectual do Paraná, ganhou força, vigor e nova seiva com o apoio pecuniário que lhe vem largamente dispensando a já benemérita União Brasileira de Educação e Ensino"" (ANUÁRIO DA FACULDADE..., 1943, p. 89).

No momento da criação, a comissão organizadora não tinha vínculo direto com as instituições culturais católicas curitibanas. No entanto, a partir de 1939, a faculdade foi controlada diretamente pelo poder do grupo católico, estando "solidamente alicerçada na austera disciplina do cristianismo, mas sem a rigidez cadavérica de organismos inadaptáveis" (ANUÁRIO DA FACULDADE..., 1943, p. 89). Com essas afirmações indicava-se que aquela instituição era o espaço de manutenção da tradição, ou melhor, dos elementos universais do catolicismo, bem como de aceitação da inovação, isto é, do progresso material advindo, particularmente, do desenvolvimento científico. No entendimento do grupo católico, a faculdade "acha-se já dotada do que há de mais moderno, eficiente e pedagógico no que concerne aos diversos gabinetes, museus, mapotecas, biblioteca de ciência e de letras" (ANUÁRIO DA FACULDADE..., 1943, p. 89).

A União Brasileira de Educação e Ensino assumiu o controle sobre a FFCL devido a uma série de problemas surgidos logo que se iniciaram as aulas. Naquele momento, o grupo do CEB assumiu o controle da referida faculdade, pois, conforme os documentos existentes, o maior problema era de ordem financeira:

vieram a faltar estes meios pecuniários, e a Faculdade estaria votada ao completo desaparecimento, com deslustre da nossa cultura intelectual, se não fora o esforço e a dedicação de um grupo de professores - Pe. Jesus Ballarin, Dr. Loureiro Fernandes e Dr. Homero Braga, secundado por outros elementos, que se puseram à frente da iniciativa, não a fazendo periclitar. (ANUÁRIO DA FACULDADE..., 19401941, p. 5) 
Essa passagem afirma o papel do laicato católico no processo de constituição da FFCL, que conseguiram

da União Brasileira de Educação e Ensino, dirigida pelos beneméritos e abnegados Irmãos Maristas, o apoio moral e material indispensável a prossecução dos trabalhos da Faculdade, recebendo destarte novo e decidido impulso, ressurgindo para honra e glória da cultura do Paraná e da grandeza do Brasil. (ANUÁRIO DA FACULDADE..., 1940-1941, p. 5-6)

Os debates iniciados em 1937, com Homero de Mello e Braga, Milton Carneiro, Omar Gonçalves e Carlos de Paula Soares, foram eclipsados no momento em que se postulava o papel decisivo do laicato católico. Havia forte associação do progresso da faculdade à ação dos católicos.

Em 1938, ainda não existiam faculdades ou/e universidades católicas no Brasil. No entanto, no Rio de Janeiro, já estava se discutindo a fundação de uma universidade católica, a qual recebeu autorização para funcionar em 1940, sendo oficializada em 1942. A FFCL do Paraná, embora coordenada por grupo católico, não foi denominada faculdade católica.

Foi a partir do final da década de 1920 que o grupo católico passou a lutar efetivamente pelo controle do ensino superior no Brasil. Naquele momento, "segundo o ideário católico, a reforma na consciência das elites só se operacionalizaria, basicamente, através do sistema de ensino superior. Ou seja, a cosmovisão católica percebe a universidade como centro nevrálgico de toda a estrutura social" (SALEM, 1982, p. 128).

A constituição de faculdades católicas era orientada pelos documentos oficiais da Igreja. No Rio de Janeiro, em 1934, os católicos organizaram o Primeiro Congresso Católico de Educação, no qual Alceu Amoroso Lima reiterava o papel do laicato no processo de organização de projetos formativos, sobretudo ao fundar instituições de ensino superior. Em 1939, foi realizado o Primeiro Concílio Plenário Brasileiro, na Bahia, no qual se expressou a última grande manifestação para criação da universidade católica.

A Associação dos Universitários Católicos (1929) e o Instituto Católico de Estudos Superiores (1932) foram considerados os embriões do projeto universitário católico no Brasil. Essas duas instituições, segundo Salem (1982, p. 120), 
embora com sentidos bastante distintos, foram as entidades geradas para uma atuação da Igreja do domínio universitário. Essas são, em suma, as instâncias mediadoras que remontam o trajeto entre a eclosão do movimento católico, em 1922, e a fundação das Faculdades Católicas, em 1941.

É nesse contexto que estamos entendendo a intervenção do laicato católico no Paraná, no final da década de 1930, ao participar ativamente no processo de constituição da Faculdade de Filosofia, Ciências e Letras do Paraná.

A FFCL foi pensada por essa intelectualidade paranaense como principal mecanismo de sistematização dos diferentes saberes estabelecidos pelas áreas científicas. Para os católicos, somente a filosofia tomista poderia desenvolver tal atividade, pois a ciência moderna reduziu a natureza e a sociedade àquilo que pode ser estudado empiricamente. No pensamento católico, essa redução implicou na separação entre a realidade e a verdade. A verdade consistia na compreensão da totalidade do real; a ciência falava do particular; já a filosofia tomista compreendia as particularidades científicas, sem ignorar a visão de totalidade.

$\mathrm{O}$ debate acerca do modelo de universidade postulado pelos católicos, particularmente sobre seu projeto político-filosófico, "remete para o diagnóstico por eles elaborado acerca do 'estado das ciências' e da própria universidade no mundo e no Brasil. O universo científico é visto como atravessando um momento de desordem e anarquia geral" (SAlem, 1982, p. 126). Assim, questionava-se sobre o sentido do desenvolvimento científico, ou seja, qual a finalidade desse saber? A questão remetia à distinção conceitual entre ciência e cientismo. Essa indagação implicava em outros dois conceitos para os católicos progresso e evolução. $\mathrm{O}$ primeiro consistia estritamente no progresso material; o último tratava dos aspectos morais e materiais.

O grupo católico paranaense afirmava que a cidade de Curitiba tinha a representação da cidade universitária. No entanto, faltava um saber aglutinador dos demais saberes. Diziam,

Os cursos superiores que foram surgindo, satisfazendo os anelos dos estudiosos e as exigências dos dias presentes, vinham mais e mais acentuar a necessidade de cursos superiores que viessem a ser o complemento indispensável de uma cultura sólida e aprimorada, tal como se objetiva nas faculdades de filosofia, ciências e letras. (ANUÁRIO DA FACULDADE..., 1940-1941, p. 5) 
A FFCL se constituiu com a finalidade de estabelecer "um clima propício ao desabrochar de uma verdadeira liderança intelectual, dentro do desordenado ambiente da cultura nacional" (ANUÁRIO DA FACULDADE..., 1940-1941, p. 41). Com essas palavras, Brasil Pinheiro Machado ${ }^{10}$ afirmava que a sólida formação moral e intelectual da juventude curitibana estava fundamentada na formação filosófica, pois somente a formação científica dos intelectuais não seria capaz de torná-los capazes para exercer a missão de conduzir o Brasil ao progresso e à civilização. À elite intelectual cabia ordenar a cultura brasileira, pois

Uma nação é uma cultura, muito mais que uma raça ou uma simples
interação psicológica. E uma cultura é um elemento vivo que cresce
e se adapta continuamente aos tempos, ou morre de inanação ou de
desagregação. Daí a necessidade de recriá-la continuamente, em
contínuo ajustamento de seus elementos às épocas, sem quebrar a
sua unidade e sua tradição. (ANUÁRIO DA FACULDADE..., 1940-1941,
p. 41)

A FFCL representava o lócus do saber desinteressado, porém, entendia o autor, ela também tinha um caráter utilitário - a "formação dos elementos destinados ao professorado secundário e à alta técnica científica aplicada" (ANUÁRIO dA FACULDADE..., 1943, p. 68). Segundo o pensamento do grupo, não era possível dissociar os elementos desinteressados dos estudos pragmáticos. Os dois saberes eram importantes para a sociedade. Entretanto, "nossos melhores estímulos devem ser dirigidos aos estudos da Faculdade de Filosofia, os quais não tendo em mira o lado prático, no sentido exclusivo de proventos pecuniários, são, no entanto, básicos para grandeza futura do povo brasileiro" (ANUÁRIO DA FACULDADE..., 1943, p. 68). Deveria-se privilegiar porque

A finalidade desses estudos é muito mais alta e, não obstante o "auri sacra fames", sempre haverá e é mister que haja a verdadeira grandeza de um povo, muito mais que a burguesia comerciante, muito mais do que uma classe de argentários - uma elite, numerosas elites de pensadores, de sonhadores idealistas, a serviço do bem comum. (ANUÁRIO DA FACULDADE..., 1943, p. 68)

O grupo católico tinha preocupação com a falta de diálogo entre a filosofia e a ciência e atribuía à Faculdade de Filosofia o papel de 
formação integral da juventude. Pensar a disciplina de filosofia nos cursos científicos representava prevenção "contra os riscos do cientismo, que 'no seu culto excessivo à ciência positiva vai à intransigência de afirmar que não há outra realidade além do mundo das sensações, das leis e dos objetos científicos"” (ANUÁrio DA FACULDADE..., 1943, p. 73). O papel da intelectualidade católica era

substituir essa concepção de ciência, para qual "só há um objeto de observação, os fatos, e uma só noção deduzida da observação, as leis", por aquela que "compreende a ciência como conhecimento tanto dos fenômenos (ciências positivas) como da substância (ciência metafísica)". (ANUÁRIO dA FACULDADE..., 1943, p. 73)

A formação do professor constituiu uma nova prerrogativa do ensino superior, pois o projeto da FFCL era completar o sistema universitário que existia no estado do Paraná, que contemplava, até aquele momento, apenas as faculdades tradicionais (Direito, Medicina e Engenharia). Nesse aspecto, a formação do professor secundário representou para o grupo católico um meio significativo para promover uma educação alicerçada nos princípios de sua filosofia, pois grande parte do quadro docente tinha vinculação com o pensamento católico.

\section{CONSIDERAÇÕES FINAIS}

A nossa tarefa foi discutir a natureza dos projetos universitários pensados na capital paranaense entre o final do século XIX e a primeira metade do século XX, bem como o papel dos intelectuais no processo de discussão e constituição do ensino superior no Estado do Paraná.

Ao longo desta análise, observamos que Rocha Pombo, o primeiro a propor a criação de uma universidade nesse estado, movia-se entre a ação parlamentar e a atuação jornalística. A sua proposta universitária acentuava o papel das letras e da filosofia no processo de formação do sábio. A proposição de Rocha Pombo defendia que a universidade deveria estar preocupada com a educação do médico, do engenheiro, ou seja, do especialista, mas precisava estabelecer a formação humanista, bem como a formação de professores. Esse projeto de ensino superior pode ser aproximado da concepção humboldtiana de universidade, na qual se conjugaria educação utilitária com formação desinteressada. 
Os intelectuais vinculados ao projeto de 1912 estavam comprometidos com a formação profissional da juventude. Nesse aspecto, seguiram a tradição das escolas e faculdades onde foram formados. Pelo exposto, pode ser concluído que Nilo Cairo e Vitor do Amaral aglutinaram em torno do projeto universitário vários intelectuais importantes e influentes no cenário político e cultural de Curitiba e do Paraná. Entre o grupo de 1912 houve interesse na criação das faculdades de formação profissional de medicina, engenharia e direito; no entanto, não existiu nenhuma pretensão de estabelecer as faculdades de letras, filosofia e de formação de professores. Neste sentido, o projeto desse grupo paranaense se aproximou do modelo napoleônico de universidade.

Os intelectuais que estabeleceram a Faculdade de Filosofia, Ciências e Letras estavam associados, em sua maioria, ao Círculo de Estudos Bandeirantes, isto é, ao pensamento católico. Esse grupo se constituiu ao longo dos anos de 1930 e congregou as principais lideranças intelectuais e políticas do Estado do Paraná. O projeto dessa faculdade recebeu o apoio da Igreja Católica por meio da Congregação Marista, bem como do estado do Paraná, pois vários dirigentes políticos do estado mantinham vínculos com o CEB e com a FFCL. Essa faculdade deveria preconizar a formação de professores para o ensino secundário, assim como a educação humanista da juventude, e expressava o modelo confessional católico que se originou na Universidade de Louvain, em 1834.

Os intelectuais paranaenses postulavam que à universidade cabia a formação de uma elite intelectual capaz de conduzir a nação. Rocha Pombo defendia o papel organizador do "sábio", capaz de dirigir a cidade, bem como de promover a elevação intelectual e moral dos outros homens; o grupo fundador da UP afirmava que os especialistas tinham a missão de organizar a nação brasileira; no final dos anos de 1930, os protagonistas da FFCL se denominavam portadores do projeto de renovação da cultura paranaense. Deste modo, os intelectuais envolvidos no processo de criação desses projetos reafirmavam o papel missionário da universidade, pois sustentavam que a ela estava reservada a formação das elites dirigentes. Nesses diferentes momentos da história cultural paranaense, os intelectuais se apresentavam na cena como agentes de vanguarda da política e da história do estado e do país, bem como os verdadeiros representantes do povo. 


\begin{abstract}
This article analyzes the journey, debates and projects of intellectuals on the topic of third level education in the light of the historical context of Paraná, in a study confined to the 1892-1938 period. It also analyzes the processes of the formation of groups, their dialogue with theoretical and philosophical thinking in general, their ideas and cultural interventions, as well as their relationships with the State and political groups in vogue in Paraná during this period. It also discusses the contribution of Paraná intellectuals to the process of the constitution and organization of third level education and emphasizes that the role of these groups was to establish cultural institutions within Paraná, without forgetting Brazilian and European political and cultural contexts as a background for the setting up of third level education. This study is based on a set of documents written and organized by these intellectuals, which permits one to affirm that these groups established third level institutions and mobilized the main personalities of the cultural and political sphere in Curitiba into placing themselves at the service of the university project in the State of Paraná.
\end{abstract}

Key-words: Intellectual. University. Human development.

\title{
NOTAS
}

1. Nasceu em Morretes (PR) em 4 de dezembro de 1859; faleceu no Rio de Janeiro em 26 de junho de 1933.

2. Foi lançada a pedra fundamental desse projeto, bem como foram organizados os programas; no entanto, esse empreendimento não foi efetivado.

3. Na obra A supremacia do ideal, Rocha Pombo citava diversos autores, como, por exemplo, Littrè, Comte, Spencer, Darwin, Pereira Barreto, Buffon, Cuvier, Condillac, Destutt-Tracy, Kant, Hegel, Renan, Turgot, Humboldt, Lamartine, Flamarion, Vitor Hugo e outros.

4. Doravante, usaremos a terminologia UP.

5. Formado em Engenharia.

6. Formado em Direito pela Faculdade de Direito de São Paulo.

7. Professor na Faculdade de Direito e membro do Círculo de Estudos Bandeirantes. O referido texto diz respeito à oração de paraninfo proferida em 1932 e publicado em 1944 na obra intitulada Diretrizes à juventude.

8. Centro cultural criado pelo laicato católico, em 1929, na capital paranaense.

9. A União Brasileira de Educação e Ensino (ABEE) era a mantenedora da Congregação Marista e antecessora da atual Associação Brasileira de Educação e Cultura (ABEC). 
10. Professor Catedrático da cadeira de História do Brasil, na FFCL do Paraná.

\section{REFERÊNCIAS}

ANUÁRIO da Faculdade de Filosofia, Ciências e Letras do Paraná. Curitiba, 1940-1943.

CAMPOS, N. de. Intelectuais paranaenses e as concepções de universidade (1892-1950). Curitiba, 2006. Tese (Doutorado em História da Educação) - Setor de Educação, Universidade Federal do Paraná.

DIRETRIZES à juventude (orações de paraninfos). Curitiba, 1944.

GRAMSCI, A. Cadernos do cárcere. Rio de Janeiro: Civilização Brasileira, 2001. v. 2.

POMBO, F. R. A supremacia do ideal: estudo sobre educação. Castro: Tipografia Echo dos Campos, 1883.

Petrucello. Curitiba: Impressora Paranaense, 1892.

ROSSATO, R. Universidade: nove séculos de história. Passo Fundo: EDIUPF, 1998.

SALEM T. Do Centro Dom Vital à universidade católica. In: SCHWARTZMAN, S. (Org.). Universidades e instituições científicas no Rio de Janeiro. Brasília: CNPq, 1982. p. 97-134. 